\title{
EXTRACTION AND CHARACTERIZATION OF GELATIN: A FUNCTIONAL BIOPOLYMER
}

\author{
MERINA PAUL DAS*, SUGUNA P. R., KARPURAM PRASAD, VIJAYLAKSHMI J. V., RENUKA M.
}

Department of Industrial Biotechnology, Bharath University, Chennai, India

Email: merinadas@gmail.com

Received: 09 Feb 2017 Revised and Accepted: 22 Jul 2017

\begin{abstract}
Objective: Gelatin is widely used biopolymer in various industries due to its excellent biocompatibility, biodegradability properties. In the present study, gelatin was extracted from fish wastes, as an alternative source.

Methods: This biopolymer was extracted from the scales of freshwater fish, Labeo rohita. After extraction, the proximate analysis and physicochemical analysis of the fish scale gelatin were carried out. This functional polymer was also characterized using different analytical methods, such as UV-vis spectroscopy, scanning electron microscopy (SEM), and X-ray diffraction (XRD) for the evaluation of crystalline and surface morphology, and fourier transform infrared spectroscopy (FTIR) for structural determination.
\end{abstract}

Results: The scales of L. rohita yield 24\% (dry weight basis) of gelatin, indicating this fish species as potential source of gelatin. The proximate analysis determined was low moisture content $(4.2 \%)$, ash $(1.4 \%)$ and high protein $(90 \%)$ content. The result of the study confirms the effectiveness of extraction method used.

Conclusion: The fish scales of $L$. rohita are found to be a sustainable and renewable source of gelatin with desirable functionalities and it is the best alternative for mammalian gelatin in food and other industries.

Keywords: Gelatin, Fish scale, Extraction, Characterization

(C) 2017 The Authors. Published by Innovare Academic Sciences Pvt Ltd. This is an open access article under the CC BY license (http://creativecommons.org/licenses/by/4.0/) DOI: http://dx.doi.org/10.22159/ijpps.2017v9i9.17618

\section{INTRODUCTION}

In recent years, there has been an increasing interest for using biodegradable materials in packaging, agriculture, food, medicine etc. A variety of blends using biopolymers can be the alternative of currently used synthetic polymeric materials. The most common and potential biopolymers are starch, gelatin, chitosan, alginate, PLA PHAs, etc. [1]. Among these, gelatin has increased global demand as it is an important functionally active biopolymer [2]. Gelatin is a naturally occurring macromolecular and biodegradable protein that is produced by the controlled partial hydrolysis of collagen synthesized from skins, white connective tissues and bones of animals which is composed of amino acid residues at different proportions and combinations [3]. Because of the favorable properties, such as high water solubility, non-toxicity, thermoreversible sol-gel transition, high mechanical strength and elasticity in a dry state, moisturizing cause by binding a plenty of water, gelatin are widely used as raw material in photography, pharmaceutical and cosmetic industries, it is used as water-soluble capsules, coating materials for oral drugs, stabilizer of photosensitive reagents in photographic films, adsorbent for diluted chemicals and adhesive agents $[4,5]$. In the food industry, gelatin is one of the water soluble polymers that can be used as an ingredient to improve the elasticity, consistency and stability of foods. They are utilized in confections (mainly for providing chewiness, texture, and foam stabilization), low-fat spreads (to provide creaminess, fat reduction and mouth feel), dairy (to provide stabilization and texturization), baked goods (to provide emulsification, gelling and stabilization) and meat products (to provide water-and fat-binding) [6]. There are two main types of gelatin. Type A, with isoionic point of 7 to 9 , is derived using exclusively acid pretreatment. Type B, with isoionic point of 4 to 5 , is the result of an alkaline pretreatment [7].

Generally, the sources of gelatin produced from bovine and pig skins and demineralized bones and hooves [8]. For several reasons there are still serious concern among the consumers to consume gelatin which produce from bovine and porcine bones and skins. This is because some problems such as religious matter, mad cow disease (Bovine Spongiform Encephalophy: BSE) and social reasons. Factors such as the outbreak of BSE and increasing demand for nonmammalian gelatin have revived the interest to discover the alternatives sources of gelatin from fish (marine and freshwater) and poultry as raw materials $[9,10]$. The waste generated from the worldwide production and processing of shell-fish and fish scales is a serious problem of growing magnitude. This abundant waste may pose environmental hazard [11]. The use of this waste for renewable products such as biopolymers is a dual-purpose opportunity [12]. Therefore, the abundance sources of fish byproduct such as bones, scales and skin can be the great sources of gelatin. Fish scales and bones are more preferable in the extraction of gelatin because it yields large amount of gelatin due to high content of amino acids (proline) compared to fish skin [13]. Thus the aims of this investigation were to extract the gelatin (Type B) from scales of $L$. rohita, a fresh water fish, to characterize and to study some its physicochemical properties.

\section{MATERIALS AND METHODS}

\section{Collection and preparation of materials}

Scales of $L$. rohita with an average body weight of 100-200 g were collected at Guntur, Andhra Pradesh, India. The fish scales were removed with hands, packaged in zip locked polyethylene bags, iced, and quickly transported to the laboratory. The scales were treated with chilled water, washing it twice to clean before being dried, finally dried and kept at $5{ }^{\circ} \mathrm{C}$ until further use. All the reagents used in this work were of analytical grade and purchased from Hi-Media (Mumbai).

\section{Extraction of gelatin}

Gelatin-Type B was extracted by alkali treatment method [14]. Dried scales were initially stirred with $5 \%$ sodium chloride $(\mathrm{NaCl})$ solution $(1 / 10, \mathrm{w} / \mathrm{v})$ for $30 \mathrm{~min}$ at room temperature. This step was repeated twice and the second step was completed by stirring with $0.4 \%$ sodium hydroxide $(\mathrm{NaOH})(1 / 10, \mathrm{w} / \mathrm{v})$ for $60 \mathrm{~min}$ to remove the non-collagenous proteins from the scales. Alkali solution was changed every $30 \mathrm{~min}$ and the third step proceeded using $10 \%$ isobutyl alcohol $(1 / 4, \mathrm{w} / \mathrm{v})$ to remove lipids from the scales. This step was repeated three times for $30 \mathrm{~min}$ in a digital linear shaker. 
The final step was demineralization with $0.5 \mathrm{~N}$ ethylenediamine tetraacetic acid (EDTA) solutions at an inherent $\mathrm{pH}$ of 7.66 for four different time periods of shaking: $12 \mathrm{~h}, 2 \mathrm{~h}, 2 \mathrm{~h}$, and $1 \mathrm{~h}$. In each step, scales were recovered by filtering through a sieve and washed with distilled water to remove any residual matter. Recovered scales were soaked in $0.05 \mathrm{M}$ acetic acid solution for 3 h. After filtering, $1 / 3(\mathrm{w} / \mathrm{v})$ water was added and heated at $60{ }^{\circ} \mathrm{C}$ overnight in an oven. This was filtered and the filtrate (dried thin films) was dried in plastic trays at room temperature using air conditioning overnight (set at $18{ }^{\circ} \mathrm{C}$, flow temperature was $10 \pm 2$ ${ }^{\circ} \mathrm{C}$ ). Dried thin films were ground using a grinder and gelatin powder was obtained.

\section{Physiochemical properties}

After gelatin extraction, quality factors were determined according to national and international standards.

\section{Gelatin yield}

The yield of gelatin was calculated based on dry weight of fish scale [15] by using the following equation:

$$
\text { Yield of gelatin }(\%)=\frac{\text { Weight of dried gelatin }(\mathrm{g})}{\text { Dry weight of fish scale }(\mathrm{g})} \times 100
$$

\section{Proximate analysis}

The moisture, ash, total protein contents and fat contents of the gelatin were determined according to the standard methods. Conversion factors were 5.51 was used for calculating the protein content of the gelatin $[16,17]$.

\section{Determination of gelatin $\mathrm{pH}$}

The $\mathrm{pH}$ of gelatin solution was determined by preparing $1 \%(\mathrm{w} / \mathrm{v})$ gelatin solution in distilled water and cool to $25{ }^{\circ} \mathrm{C}$ in a water bath and $\mathrm{pH}$ was measured.

\section{Determination melting temperature}

The method for melting point measurement was described by Choi and Regenstein [18]. The sample (1 g) was heated and stirred using a spatula and repeated three times.

\section{Characterization of biopolymer}

\section{UV-vis spectroscopy analysis}

The UV-vis absorption spectrum of gelatin was recorded using a UVvis double-beam spectrophotometer (UV 8500 II, Techcomp) in the range of 200-400 nm.

\section{Fourier transform infrared (FTIR) spectroscopy analysis}

Fourier transform infrared (FTIR) (Jasco-FTIR 4100 type A, Japan) spectrum was recorded to detect the chemical and structural nature of gelatin powder. $2 \mathrm{mg}$ of gelatin powder were mixed with $100 \mathrm{mg}$ of potassium bromide [19] and placed on the crystal cell of the FTIR spectrophotometer. Measurement was performed at $4000-400 \mathrm{~cm}^{-1}$ at room temperature and automatic signals were collected from 32 scans at a resolution of $4 \mathrm{~cm}^{-1}$.

\section{$\mathrm{X}$-Ray diffraction analysis of gelatin}

Further characterization of gelatin powder was done using X-ray diffraction technique. It was carried out in an X-ray diffractometer (X'Pert Pro A Analytical) operated at $45 \mathrm{kV}$ voltage and $40 \mathrm{~mA}$ current. The pattern was recorded by $\mathrm{Cu} K \alpha$ radiation in a $\theta-2 \theta$ configuration.

\section{Scanning electron microscopy (SEM) analysis}

The surface morphology of gelatin was analyzed by scanning electron microscope (FEI Quanta 200 SEM). The surface of dried gelatin was coated with gold in vacuum using sputter coater, and was photographed.

\section{Statistical analysis}

All determinations were carried out in triplicates and data were analyzed by ANOVA followed by Tukey's multiple comparisons test for significant differences. Values were considered significant at $\mathrm{p}<0.05$.

\section{RESULTS AND DISCUSSION}

\section{Yield of gelatin}

The yield of extracted light yellow color gelatin was $24 \%$ based on dry weight basis from fish scales. This result was higher than that reported by Jamilah and Harvinder [10], with the yield of extracted gelatin of red tilapia and black tilapia of $7.81 \%$ and $5.39 \%$, respectively.

\section{Physico-chemical and proximate composition of gelatin}

The proximate compositions of extracted gelatins are tabulated in table 1. The moisture content of the fish scale gelatin was $4.2 \%$ which is much below the prescribed limit of $15 \%$ [20] for edible gelatin. The sample gave a low ash content of $1.4 \%$ that well below the recommended maximum of $2.6 \%$ [21]. The extracted gelatin showed high protein $(90 \%)$ content as protein is the main constituent of gelatin. The gelatin was found to be low lipid content (1.05\%). pH value of gelatin extracted by an alkali pretreatment method from fish scale found to be 4.35 which may be depend on the extraction method, because it has been already reported that alkali pretreatment results in Type B gelatin with $\mathrm{pH}$ in the range of 4-5 [8]. The melting temperature of the extracted Type B gelatin was 27 ${ }^{\circ} \mathrm{C}$ which significantly affects its gelling properties.

\section{Characterization of biopolymer}

To identify the amino acids contributing to the specific of gelatin, UV-vis spectrophotometer was used to characterize in the range of wavelength 200-400 nm. Chromophore groups which give absorption at $210-240 \mathrm{~nm}$ indicate the presence of characteristic peptide bond fragments from each of the gelatin [22]. Fig. 1 shows the characteristic UV-vis spectrum of gelatin at $224 \mathrm{~nm}$, confirms the distinctive structure of gelatin.

The application of gelatin depends on the chemical stability without undergoing degradation like partial oxidation. FTIR measurement was made to identify the possible biomolecules, bonds responsible for the structural and functional stabilization of the gelatin extracted from the fish scales. Proteins are comprised of amino acids joined together by amide bonds. The polypeptide and protein repeat units give rise to nine characteristic infrared (IR) absorption bands, namely; amide A, B, and IVII [23]. Amide bands represent different vibrational modes of the peptide bond. The absorption bands of gelatin in the IR spectra are situated in the amide band region; amide-I represents $\mathrm{C}=0$ stretching/hydrogen bonding couple with COO, amide-II represents bending vibration of $\mathrm{N}-\mathrm{H}$ groups and stretching vibrations of C-N groups, Amide-III is related to the vibrations in plane of C-N and N-H groups of bound amide [24]. Fig. 2 shows the peaks of the gelatin at $3433 \mathrm{~cm}^{-1}$ attributed to the presence of hydrogen bond water and amide-A, 1630 $\mathrm{cm}^{-1}$ peaks corresponds to the occurrence of amide-I, at $1565 \mathrm{~cm}^{-1}$ is indicating amide-II, band at $1240 \mathrm{~cm}^{-1}$ indicates the amide-III, peaks ranges from $1460 \mathrm{~cm}^{-1}$ to $1380 \mathrm{~cm}^{-1}$ were attributed to the symmetric and asymmetric bending vibrations of methyl group [25-27].

Table 1: Proximate and physico-chemical analysis of gelatin

\begin{tabular}{ll}
\hline Factors & Fish scale gelatin \\
\hline Moisture & $4.2 \%$ \\
Protein & $90 \%$ \\
Ash & $1.4 \%$ \\
Lipid & $1.05 \%$ \\
pH & 4.35 \\
Melting temperature & $27^{\circ} \mathrm{C}$ \\
\hline
\end{tabular}




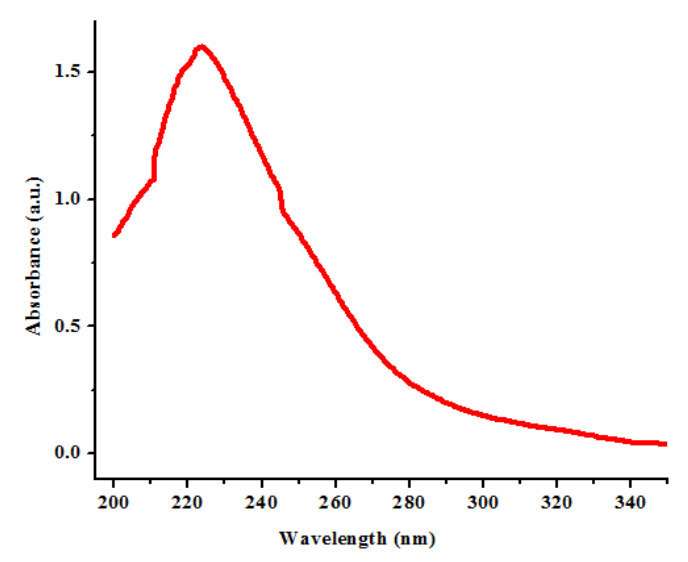

Fig. 1: UV-vis absorption spectrum of fish scale gelatin

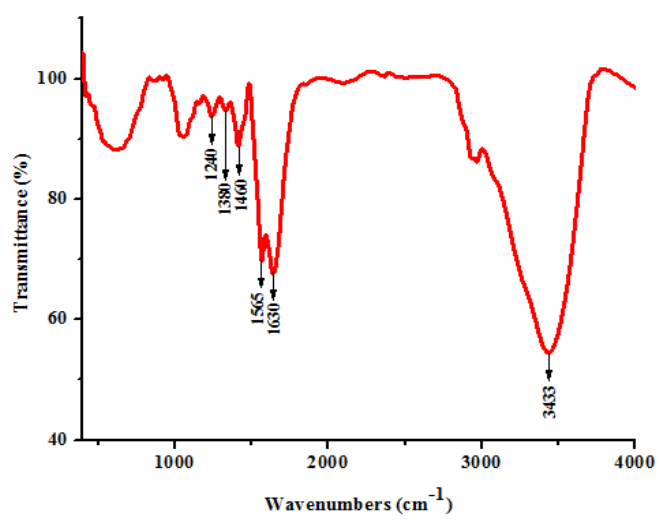

Fig. 2: FTIR spectrum of gelatin

Porosity characterization is based on the presence of open pores which are related to properties such as permeability and surface area of the porous structure. The microstructure obtained by SEM for the gelatin showed that polymers have an array of hollow cells that resembles spherical particle structures (fig. 3). Since a higher density of a scaffold usually leads to higher mechanical strength while a high porosity provides a favorable biological environment, a balance between the porosity and density for a scaffold must be established for the specific application [28]. The diffractogram pattern acquired on the pure gelatin powder were typical of a partially crystalline gelatin with a sharp peak with low intensity located at $2 \theta=\sim 7^{\circ}$ and a broad peak located at $2 \theta=\sim 19^{\circ}$, shown in fig. 4 . These characteristic peaks are usually assigned to the triplehelical crystalline structure in gelatin $[29,30]$.

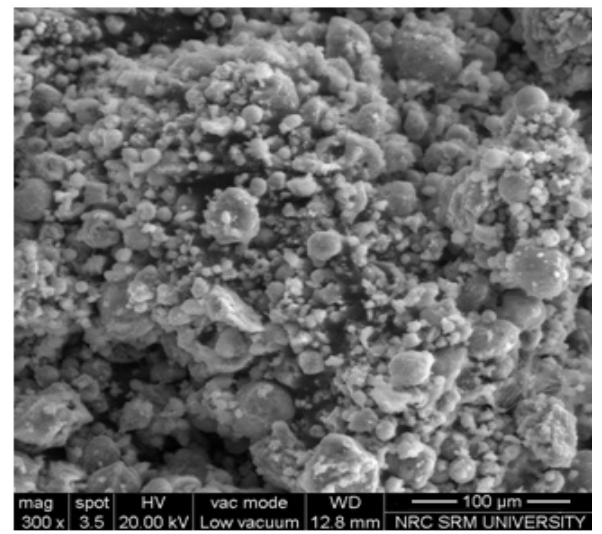

Fig. 3: SEM micrograph of gelatin extracted from fish scale

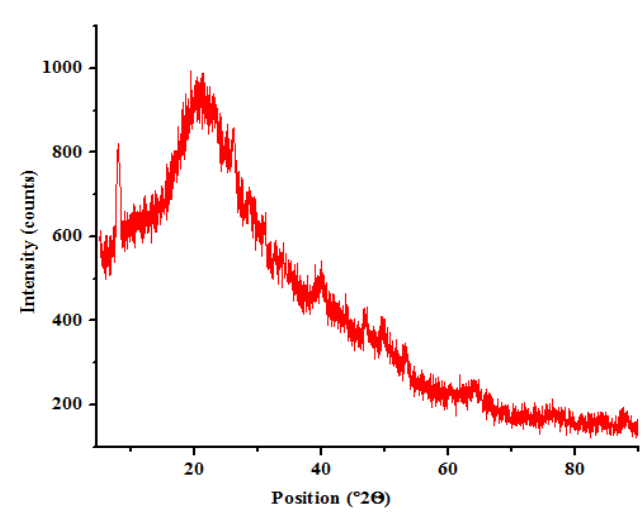

Fig. 4: XRD pattern of fish scale gelatin

\section{CONCLUSION}

This study revealed the potential of L. rohita scale as raw material for gelatin production, giving relatively high yield. Gelatin was characterized using UV-vis, FTIR, SEM and XRD methods. Morphological investigation showed that this polymer exhibit microporous morphology, FTIR spectrum indicates chemical bond formation of gelatin whereas XRD analysis revealed the crystalline structure of it. It also shows high protein content $(90 \%)$ with low moisture (4.2\%) and ash (1.4\%) content. In brief, fish scale is a costeffective and environmentally friendly source of gelatin which can be used in various industrial applications.

\section{ACKNOWLEDGEMENT}

The authors convey their thanks to Department of Industrial Biotechnology, Bharath University, Chennai, for providing laboratory facilities. The author also acknowledges SRM University, Chennai for providing support in carrying out SEM, and IIT, Chennai for FTIR and XRD analysis.

\section{CONFLICT OF INTERESTS}

Declared none

\section{REFERENCES}

1. Akter N, Khan RA, Salmieri S, Sharmin N, Dussault D, Lacroix M. Fabrication and mechanical characterization of biodegradable and synthetic polymeric films: effect of gamma radiation. Radiat Phys Chem 2012;81:995-8.

2. Shyni K, Hema GS, Ninan G, Mathew S, Joshy CG, Lakshmanan PT. Isolation and characterization of gelatin from the skins of skipjack tuna (Katsuwonus pelamis), dog shark (Scoliodon sorrakowah), and rohu (Labeo rohita). Food Hydrocolloid 2014;39:68-76.

3. Marfil PH, Anhe AC, Telis VR. Texture and microstructure of gelatin/corn starch-based gummy confections. Food Biophys 2012;7:236-43.

4. Bessho M, Furuta M, Kojima T, Okuda S, Hara M. Gelatin hydrogels cross-linked by c-ray irradiation: materials for absorption and release of dye. J Biomater Sci Polym Ed 2005;16:715-24.

5. Wangtueai S, Noomhorm A. Processing optimization and characterization of gelatin from lizardfish (Saurida spp.) scales. LWT-Food Sci Technol 2009;42:825-34.

6. Karim AA, Bhat R. Fish gelatin: properties, challenges, and prospects as an alternative to mammalian gelatins. Food Hydrocolloid 2009;23:563-76.

7. Gómez-Guillen MC, Ihl M, Bifani V, Silva A, Montero P. Edible films made from tuna-fish gelatin with antioxidant extracts of two different murta ecotypes leaves. Food Hydrocolloid 2007;21:1133-43.

8. Baziwane D, He Q. Gelatin: the paramount food additive. Food Rev Int 2003;19:423-35.

9. Ruri Widyasari, Saroat Rawdkuen. Extraction and characterization of gelatin from chicken feet by acid and ultrasound assisted extraction. Food Appl Biosci J 2014;2:85-97. 
10. Jamilah B, Harvinder KG. Properties of gelatins from skins of fish-black tilapia (Oreochromis mossambicus) and red tilapia (Oreochromis nilotica). J Food Chem 2002;77:81-4.

11. Mejia-Saules JM, Waliszewski KN, Garcia MA, Cruz-Camarillo R. The use of crude shrimp shell powder for chitinase production by Serratia marcescens WF. Food Technol Biotechnol 2006;44:646-51.

12. Gildberg A, Stenberg EA. Utilisation of male arctic capelin and atlantic cod intestines for fish sauce production--evaluation of fermentation conditions. Process Biochem 2001;36:809-12.

13. Salamiah Zakaria, Nurul Hidayah, Abu Bakar. Extraction and characterization of gelatin from black telapia (Oreochromis niloticus) scales and bones. ICASETNR-15, Kota Kinabalu, Malaysia; 2015.

14. Mehmet Tolga Dinçer, Ozlem Yeşim Agçay, Hülya Sargin, Huriye Bayram. Functional properties of gelatin recovered from scales of farmed sea bass (Dicentrarchus labrax). Turk J Vet Anim Sci 2015;39:102-9.

15. Kaewruang $\mathrm{P}$, Benjakul S, Prodpran T, Nalinanon S. Physicochemical and functional properties of gelatin from the skin of unicorn leatherjacket (Aluterus monoceros) as affected by extraction conditions. Food Biosci 2013;2:1-9.

16. Iran national standards, Gelatin Quality Test Methods; 1994. p. 3474, 1-8.

17. AOAC. Official Methods of Analysis. Association of Official Analytical Chemists, 17th Ed; 2000.

18. Choi SS, Regenstein JM. Physichochemical and sensory characteristics of fish gelatin. J Food Sci 2000;65:194-9.

19. Muyonga JH, Cole CGB, Duodu KG. Fourier transform infrared (FTIR) spectroscopic study of acid soluble collagen and gelatin from skins and bones of young and adult Nile perch (Lates niloticus). Food Chem 2004;86:325-32.

20. Gelatin Manufacturers of Europe. Standardised methods for the testing of edible gelatine. In Gelatine monograph. 4, Avenue E. Van Nieuwenhuyse, B-1160 Bruxelles; 2005. p. 104.
21. Jones NR. Uses of gelatin in edible products. In: Ward AG, Courts A. Eds. The science and technology of gelatin. New York: Academic Press; 1977. p. 366-95.

22. Sandra Hermanto, La Ode Sumarlin, Widya Fatimah. Differentiation of bovine and porcine gelatin based on spectroscopic and electrophoretic analysis. J Food Pharm Sci 2013;1:68-73.

23. Kong J, Yu S. Fourier transform infrared spectroscopic analysis of protein secondary structures. Acta Biochim Biophys Sin 2007;39:549-59.

24. Nur Hanani ZA, Roos YH, Kerry JP. Fourier transform infrared (FTIR) spectroscopic analysis of biodegradable gelatin films immersed in water. International Congress on Engineering and Food, Proceedings; 2011.

25. Suneeta kumari, Rath P, Sri Hari Kumar A. Chitosan from shrimp shell (crangon crangon) and fish scales (Labeo rohita) extraction and characterization. Afr J Biotechnol 2016;15:1258-68.

26. Hoque MS, Benjakul S, Prodpran T. Effect of heat treatment of film-forming solution on the properties of film from cuttlefish (Sepia pharaonis) skin gelatin. J Food Eng 2010;96:66-73.

27. Bergo P, Sobral PJA. Effects of platicizer on physical properties of pigskin gelatin films. Food Hydrocolloid 2007;21:1285-9.

28. Jakir Hossana Md, Gafurb MA, Kadirb MR, Mohammad Mainul Karima. Preparation and characterization of gelatin hydroxyapatite composite for bone tissue engineering. Int J Eng Technol 2014u;14:24-32.

29. Yakimets I, Wellner N, Smith A, Wilson R, Farhat I, Mitchell J. Mechanical properties with respect to water content of gelatin films in glassy state. Polymer 2005;46:12577-85.

30. Pena C, de la Caba K, Eceiza A, Ruseckaite R, Mondragon I. Enhancing water repellence and mechanical properties of gelatin films by tannin addition. Bioresour Technol 2010;101:6836-42.

\section{How to cite this article}

- $\quad$ Merina Paul Das, Suguna PR, Karpuram Prasad, Vijaylakshmi JV Renuka M. Extraction and characterization of gelatin: a functional biopolymer. Int J Pharm Pharm Sci 2017;9(9):239-242. 